\title{
推迟拔节水及其灌水量对小麦耗水量和耗水来源及农田蒸散量的影响
}

\author{
王红光 于振文 ${ }^{*}$ 张永丽 王 东
}

山东农业大学农业部作物生理生态与栽培重点开放实验室, 山东泰安 271018

摘 要: 于 2007-2008 和 2008-2009 小麦生长季, 以高产中筋冬小麦品种济麦 22 为材料, 采用测墑补灌的方法, 研 究推迟拔节水及不同灌水水平对冬小麦耗水量、耗水来源、单位土地面积上旗叶叶面积和蒸腾速率、株间蒸发量、 籽粒产量及水分利用效率的影响。结果表明, 测墒补灌后 $0 \sim 140 \mathrm{~cm}$ 土层能够达到目标含水量。相同补灌时期, 随补 灌水平的提高, 拔节至开花阶段日耗水量增大, $0 \sim 120 \mathrm{~cm}$ 土层䛎水消耗量减小, 生育期总灌水量和田间耗水量增加, 土壤䛎水消耗量先增加后减小, 土壤䛎水消耗量和降水量占田间耗水量的比例降低。相同补灌水平, 由拔节期推迟至 拔节后 $10 \mathrm{~d}$ 补灌则麦田日耗水量减小，挑旗期日耗水量增大，拔节至开花阶段 80 120 cm 土层土壤咜水消耗量增加， 生育期总灌水量和田间耗水量亦增加，降水量、灌水量和土壤䛎水消耗量占田间耗水量的比例不变; 灌浆初期单位土 地面积上旗叶叶面积和蒸腾速率降低, 株间蒸发量增加; 公顷穗数降低, 穗粒数、千粒重、籽粒产量、水分利用效率 和灌水生产效率增加。本试验条件下, 在拔节后 $10 \mathrm{~d}$ 补灌至 $0 \sim 140 \mathrm{~cm}$ 土层平均土壤相对含水量为 $75 \%$, 开花期补灌 至 70\% (2007-2008 年度)是兼顾节水、高产的最优处理。

关键词: 冬小麦; 测墒补灌; 耗水量; 株间蒸发量; 水分利用效率

\section{Effects of Delayed Irrigation at Jointing Stage and Irrigation Level on Con- sumption Amount and Resources of Water in Wheat and Farmland Evapotranspiration}

\author{
WANG Hong-Guang, YU Zhen-Wen ${ }^{*}$, ZHANG Yong-Li, and WANG Dong \\ Key Laboratory of Crop Ecophysiology and Cultivation, Ministry of Agriculture, Shandong Agricultural University, Tai'an 271018, China
}

\begin{abstract}
Water-saving irrigation is a hotspot in cultivation research of winter wheat (Triticum aestivum L.). Many investigations have been carried out to reduce the irrigation frequency and water amount. However, the conclusions are quite different due to the great discrepancies on precipitation and experimental condition. In this study, a strategy of water-controlled irrigation based on measuing soil water content was adopted, and several delayed irrigation treatments were tested for their effects on water consumption, water use efficiency (WUE), and wheat yield in two sites of Shandong province, China in 2007-2008 and 2008-2009 growing seasons. The expected water content of $0-140 \mathrm{~cm}$ soil layer was designed for $65-80 \%$ in different treatments, and two irrigations were given at jointing or $10 \mathrm{~d}$ after jointing and flowering stages. In the treatments irrigated at the same time, the daily water consumption from jointing to flowering stage and the water consumption amount in the whole growth duration increased with promoting the level of supplemental irrigation, but the soil water consumption amount in $0-120 \mathrm{~cm}$ soil layer decreased. The consumption amount of soil water showed an increase-decrease trend, and its percentage to the total water consumption amount decreased. Simultaneously, the comsumption percentage of precipitation to the total water consumption amount was also reduced. Under the same irrigation level, compared with normal irrigation at jointing, the delayed irrigation (at $10 \mathrm{~d}$ after jointing) reduced the daily water consumption from jointing to $10 \mathrm{~d}$ after jointing stage, but promoted the daily water consumption at flagging stage. From jointing to flowering stage, the comsumption amont of soil water in $80-120 \mathrm{~cm}$ soil layer, the total water comsumption amount increased with the more irrigation water supplied. However, the comsumption percentages of precipitation, supplemental irrigation, and soil water were in minor changes. At early filling stage, the flag leaf area and the transpiration per unit area of soil decreased and the evaporation increased in the delayed irrigation treatment. Although reduced spike number per hectare, the grain number, thousand-grain weight, grain yield, WUE, and irrigation production efficiency were higher in the delayed irrigation treatment than in the treatment of irrigation at jointing stage. Under the experimental condition (2007-2008 growing season), the
\end{abstract}

\footnotetext{
本研究由国家自然科学基金项目(30871478)和农业部现代小麦产业技术体系项目(nycytx-03)资助。

*通讯作者(Corresponding author): 于振文, E-mail: yuzw@sdau.edu.cn; Tel: 0538-8241484

第一作者联系方式: E-mail: jlwanghongguang@163.com

Received(收稿日期): 2010-02-10; Accepted(接受日期): 2010-04-21.
} 
first supplemental irrigation at $10 \mathrm{~d}$ after joining with a relative water content of $75 \%$ in $0-140 \mathrm{~cm}$ soil layer and the second irrigation at flowering with a relative water content of $70 \%$ were considered to be an optimal water-saving management for wheat high-yielding production.

Keywords: Winter wheat; Supplemental irrigation based on testing soil moisture; Water consumption amount; Evaporation; Water use efficiency

水资源不足是限制我国北方小麦生产的主要因 素，提高水分利用效率和灌溉水利用率是小麦生产 迫切需要解决的问题 ${ }^{[1]}$ 。有研究表明, 在底墑充足条 件下, 春季灌两水, 每次灌水量 $60 \mathrm{~mm}$ 即可满足小 麦对水分的需求 ${ }^{[2]}$, 拔节前轻度水分亏缺不会对小 麦籽粒产量造成不利影响 ${ }^{[3]}$, 甚至会使其略有增 加 ${ }^{[4]}$ 。小麦拔节期 0 50 $\mathrm{cm}$ 土层平均含水量的调亏 下限为 $65 \%$, 孕穗至灌浆前期 $0 \sim 100 \mathrm{~cm}$ 土层含水量 下限为 $60 \%$, 灌浆后期 0 100 cm 土层含水量下限为 $50 \%{ }^{[5]}$ 。在不降低作物产量的情况下减少作物蒸腾量, 是节水农业的核心问题 ${ }^{[6]}$ 。关于灌水次数和灌水量 及小麦各生育时期土壤水分亏缺下限已有很多研究, 但在高产条件下推迟拔节水和不同灌水水平对小麦 耗水特性和农田蒸散量的影响研究较少。本试验采 用测墑补灌的方法, 研究高产条件下推迟拔节水和 不同灌水水平对冬小麦耗水量、耗水来源、旗叶蒸 腾速率、株间蒸发量、籽粒产量及水分利用效率的 影响, 以期为小麦节水高产栽培提供理论依据。

\section{1 材料与方法}

\section{1 试验设计}

于 2 个小麦生长季分别在山东泰安山东农业大 学实验农场 $\left(117.15^{\circ} \mathrm{E}, 36.15^{\circ} \mathrm{N}\right)$ 和在山东充州小孟 镇史王村大田 $\left(116.41^{\circ} \mathrm{E}, 35.41^{\circ} \mathrm{N}\right)$ 进行田间试验, 供 试品种均为高产中筋品种济麦 22 。

2007-2008 生长季试验田土壤类型为棕壤, 播 种前 $0 \sim 20 \mathrm{~cm}$ 土层含有机质 $1.4 \%$ 、全氮 $0.1 \%$ 、碱解 氮 $94.2 \mathrm{mg} \mathrm{kg}^{-1}$ 、速效磷 $38.2 \mathrm{mg} \mathrm{kg}^{-1}$ 、速效钾 $80.0 \mathrm{mg}$ $\mathrm{kg}^{-1}, 0 \sim 20 、 20 \sim 40 、 40 \sim 60 、 60 \sim 80 、 80 \sim 100 、 100 \sim 120$ 、 120 140、140 160、160 180 和 $180 \sim 200 \mathrm{~cm}$ 土层的 土壤含水量分别为 $17.8 \% 、 18.4 \% 、 20.2 \% 、 19.6 \%$ 、 $20.4 \% 、 23.4 \% 、 28.3 \% 、 28.9 \% 、 25.6 \%$ 和 $26.4 \%, 0 \sim 140$ $\mathrm{cm}$ 土层平均土壤容重为 $1.5 \mathrm{~g} \mathrm{~cm}^{-3}$, 平均田间持水 量为 $25.2 \%$ 。小麦生育期间降水量, 播种至冬前期为 $21.1 \mathrm{~mm}$, 冬前至返青期为 $12.5 \mathrm{~mm}$, 返青至拔节期 为 $13.8 \mathrm{~mm}$, 拔节至开花期为 $57.3 \mathrm{~mm}$, 开花至成熟 期为 $37.0 \mathrm{~mm}$ 。设 7 个处理(表 1), 除拔节期和开花

表 1 不同处理的目标相对含水量和实际相对含水量 $(0 \sim 140 \mathrm{~cm}$ 土层平均值 $)$ 及灌水量

Table 1 Expected relative water content and actually relative water content $(0-140 \mathrm{~cm})$ and irrigation amount of different treatments

\begin{tabular}{|c|c|c|c|c|c|c|c|c|}
\hline \multirow[b]{2}{*}{$\begin{array}{c}\text { 处理 } \\
\text { Treatment }\end{array}$} & \multicolumn{4}{|c|}{ 拔节期或拔节后 $10 \mathrm{~d}$ Jointing or $10 \mathrm{~d}$ after jointing stage } & \multicolumn{4}{|c|}{ 开花期 Flowering stage } \\
\hline & $\begin{array}{c}\text { 目标相对含水 } \\
\text { 量 } \mathrm{ERWC} \\
(\%)\end{array}$ & $\begin{array}{c}\text { 相对含水量 } \\
\text { RWC } \\
(\%)\end{array}$ & $\begin{array}{c}\text { 相对误差 } \\
\mathrm{RE} \\
(\%)\end{array}$ & $\begin{array}{c}\text { 灌水量 } \\
\text { Irrigation amount } \\
(\mathrm{mm})\end{array}$ & $\begin{array}{c}\text { 目标相对含水量 } \\
\text { ERWC } \\
(\%)\end{array}$ & $\begin{array}{c}\text { 相对含水量 } \\
\text { RWC } \\
(\%)\end{array}$ & $\begin{array}{c}\text { 相对误差 } \\
\text { RE } \\
(\%)\end{array}$ & $\begin{array}{c}\text { 灌水量 } \\
\text { Irrigation amount } \\
(\mathrm{mm})\end{array}$ \\
\hline \multicolumn{9}{|l|}{ 2007-2008 } \\
\hline W0 & - & - & - & 0 & - & - & - & 0 \\
\hline W1 & 65 & 64.8 & 0.3 & 1.0 & 70 & 70.4 & 0.6 & 55.3 \\
\hline W2 & 75 & 74.2 & 1.1 & 54.0 & 70 & 69.8 & 0.3 & 34.3 \\
\hline W3 & 80 & 80.9 & 1.1 & 81.0 & 70 & 69.5 & 0.7 & 21.4 \\
\hline W4 & 65 & 64.3 & 1.1 & 7.0 & 70 & 70.7 & 1.0 & 55.0 \\
\hline W5 & 75 & 74.1 & 1.2 & 60.0 & 70 & 69.1 & 1.3 & 29.5 \\
\hline W6 & 80 & 80.6 & 0.8 & 87.0 & 70 & 71.1 & 1.6 & 19.9 \\
\hline \multicolumn{9}{|l|}{ 2008-2009 } \\
\hline W0 & - & - & - & 0 & - & - & - & 0 \\
\hline W1 & 75 & 75.4 & 0.5 & 23.5 & 75 & 75.8 & 1.1 & 35.9 \\
\hline W2 & 75 & 74.7 & 0.4 & 38.1 & 75 & 75.2 & 0.3 & 27.4 \\
\hline
\end{tabular}

2007-2008 年度 W4、W5 和 W6 处理及 2008-2009 年度 W2 处理在拔节后 $10 \mathrm{~d}$ 灌水，其他处理(不含 W0)拔节期灌水。

Treatments W4, W5, and W6 in 2007-2008 and W2 in 2008-2009 growing season were irrigated 10 d after joining stage, and other treatments except for W0 were irrigated at jointing stage. ERWC: expected relative water content; RWC: relative water content; RE: relative error. 
期以外，其余生育时期均不灌水。小区面积为 $2 \mathrm{~m} \times 4$ $\mathrm{m}=8 \mathrm{~m}^{2}$, 小区之间设 $1 \mathrm{~m}$ 宽的隔离带, 随机区组排 列, 3 次重复。基肥用量为每公顷纯氮 $105 \mathrm{~kg}, \mathrm{P}_{2} \mathrm{O}_{5}$ $112.5 \mathrm{~kg}, \mathrm{~K}_{2} \mathrm{O} 112.5 \mathrm{~kg}$, 拔节期每公顷追施 $135 \mathrm{~kg}$ 纯氮。所施肥料为尿素(含 $\mathrm{N} 46.4 \%$ )、磷酸二铵(含 $\mathrm{P}_{2} \mathrm{O}_{5} 46 \%, \mathrm{~N} \mathrm{18 \%}$ )、硫酸钾(含 $\mathrm{K}_{2} \mathrm{O} 52 \%$ )。2007 年 10 月 10 日播种, 四叶期定苗, 基本苗 180 株 $\mathrm{m}^{-2}$ 。 其他管理措施同高产田。

2008-2009 生长季试验田土壤类型为棕壤, 播 种前 $0 \sim 20 \mathrm{~cm}$ 土层含有机质 $1.3 \%$ 、全氮 $0.1 \%$ 、碱解 氮 $100.2 \mathrm{mg} \mathrm{kg}^{-1}$ 、速效磷 $24.9 \mathrm{mg} \mathrm{kg}^{-1}$ 、速效钾 108.3 $\mathrm{mg} \mathrm{kg}{ }^{-1}$ 。0 20、20 40、40 60、60 80、80 100、 $100 \sim 120 、 120 \sim 140 、 140 \sim 160 、 160 \sim 180$ 和 $180 \sim 200 \mathrm{~cm}$ 土层的土壤含水量分别为 $18.7 \% 、 18.6 \% 、 19.8 \%$ 、 $20.3 \% 、 21.8 \% 、 22.1 \% 、 20.3 \% 、 20.6 \% 、 20.9 \%$ 和 $21.7 \%$, 0 140 cm 土层平均土壤容重为 $1.6 \mathrm{~g} \mathrm{~cm}^{-3}$, 平均田间 持水量为 $24.5 \%$ 。 小麦生育期间降水量, 播种至冬前 期为 $13.6 \mathrm{~mm}$, 冬前至返青期为 $16.7 \mathrm{~mm}$, 返青至拔 节期为 $28.9 \mathrm{~mm}$, 拔节至开花期为 $54.9 \mathrm{~mm}$, 开花至 成熟期为 $26.3 \mathrm{~mm}$ 。设 3 个处理(表 1), 除拔节期和 开花期以外，其余生育时期均不灌水。小区面积为 4 $\mathrm{m} \times 4 \mathrm{~m}=16 \mathrm{~m}^{2}$, 小区之间设 $2 \mathrm{~m}$ 宽的隔离带, 随机 区组排列, 3 次重复。施肥、播种和定苗及田间管理 措施均与上一年度相同。

\section{2 土壤含水量测定及灌水量计算}

采用干重法测定土壤质量含水量。灌水量 $m$ $(\mathrm{mm})=10 \rho b H\left(\beta_{i}-\beta_{j}\right)^{[7]}$, 式中, $H$ 为土层深度 $(\mathrm{cm})$, 本试验的土层深度为 $140 \mathrm{~cm} ; \rho b$ 为土壤干容重 $(\mathrm{g}$ $\mathrm{cm}^{-3}$ ); $\beta_{i}$ 为目标含水量 (田间持水量乘以目标相对含 水量); $\beta_{j}$ 为灌溉前土壤含水量。用水表计量灌水量。

1.3 田间耗水量及水分利用效率和灌水生产效 率计算

采用水量平衡法计算田间耗水量 ${ }^{[8]}$ 。

水分利用效率 $W U E=Y / E T_{\alpha}{ }^{[9]} ;$ 灌水生产效率 $I P E=\Delta Y / I^{[10]}$ 。式中, $W U E$ 和 $I P E$ 分别为水分利用效 率 $\left(\mathrm{kg} \mathrm{hm}^{-2} \mathrm{~mm}^{-1}\right)$ 和灌水生产效率 $\left(\mathrm{kg} \mathrm{h}^{-2} \mathrm{~mm}^{-1}\right) ; Y$ 为籽粒产量 $\left(\mathrm{kg} \mathrm{hm}^{-2}\right) ; \Delta Y$ 为灌溉后增加的产量 $(\mathrm{kg}$ $\left.\mathrm{hm}^{-2}\right), E T_{\alpha}$ 为小麦生育期间实际耗水量 $(\mathrm{mm})$, 是各 阶段耗水量之和; $I$ 为实际灌水量 $(\mathrm{mm})$ 。

1.4 株间蒸发量及单位土地面积上旗叶叶面积 和蒸腾速率测定

用内径 $75 \mathrm{~mm}$ 、壁厚 $5 \mathrm{~mm}$ 的 PVC 管自制小型 蒸发器, 置于冬小麦行间土壤, 测定株间蒸发量 ${ }^{[11]}$ 。
参照叶面积指数计算方法 ${ }^{[12]}$ 确定单位土地面积 的旗叶叶面积, $A_{f} P A=D A_{f}$, 式中, $A_{f} P A$ 为单位土地 面积的旗叶叶面积, $D$ 为群体密度 $\left(\mathrm{m}^{-2}\right), A_{f}$ 为单叶旗 叶叶面积 $\left(\mathrm{m}^{2}\right)$ 。

用 Li-6400 便携式光合仪(Li-Cor，USA)测定旗 叶蒸腾速率, 旗叶蒸腾速率 $\left(T, \mathrm{mmol} \mathrm{H}_{2} \mathrm{O} \mathrm{m}^{-2} \mathrm{~s}^{-1}\right)$ 与 单位土地面积上旗叶叶面积 $\left(A_{f} P A\right)$ 的乘积为单位土 地面积上旗叶蒸腾速率 $(T P A)$, 即 $T P A=T A_{f} P A$ 。

\section{5 数据分析}

采用 DPS 7.05 和 SPSS 11.5 统计分析软件分析 数据, 用 Microsoft Excel 2003 软件计算和绘图。

\section{2 结果与分析}

2.1 不同处理对小麦拔节至开花和开花至成熟 阶段 $0 \sim 200 \mathrm{~cm}$ 土层土壤咜水消耗量的影响

2007-2008 生长季, 拔节至开花期 W0 和 W1 处理 0 80 $\mathrm{cm}$ 土层土壤财水消耗量显著高于其他灌 水处理(图 1), 说明灌拔节水显著降低该阶段 $0 \sim 80$ $\mathrm{cm}$ 土层土壤咜水消耗量; 比较相同补灌时期不同补 灌量的各处理的 $0 \sim 120 \mathrm{~cm}$ 土层土壤咜水消耗量, 拔 节期灌水的表现为 $\mathrm{W} 1>\mathrm{W} 2>\mathrm{W} 3$, 拔节后 $10 \mathrm{~d}$ 灌水 的表现为 $\mathrm{W} 4>\mathrm{W} 5>\mathrm{W} 6$ (图 1), 说明拔节期补灌水平 越高, $0 \sim 120 \mathrm{~cm}$ 土层土壤䛎水消耗量越低; 相同补 灌水平不同补灌时期的各处理间比较, $0 \sim 80 \mathrm{~cm}$ 土层 土壤咜水消耗量为 $\mathrm{W} 2>\mathrm{W} 5, \mathrm{~W} 3>\mathrm{W} 6$, 而 $80 \sim 120 \mathrm{~cm}$ 土层土壤䛎水消耗量为 $\mathrm{W} 5>\mathrm{W} 2, \mathrm{~W} 6>\mathrm{W} 3$ (图 1), 说 明拔节后 $10 \mathrm{~d}$ 补灌比拔节期补灌降低了拔节至开花 阶段 0 80 cm 土层土壤㲸水消耗量, 提高了 $80 \sim 120$ $\mathrm{cm}$ 土层土壤咜水消耗量。

开花至成熟期, $W 0$ 处理 100 160 cm 土层土壤䛎 水消耗量显著高于灌水处理(图 1), 说明不灌水显著 提高了该阶段 100 160 cm 土层土壤䛎水消耗量; 相 同补灌时期不同补灌量的各处理比较, $0 \sim 100 \mathrm{~cm}$ 土层 土壤䛎水消耗量表现为 $\mathrm{W} 3>\mathrm{W} 2>\mathrm{W} 1, \mathrm{~W} 6>\mathrm{W} 5>\mathrm{W} 4$ (图 1), 说明随拔节期补灌水平的提高使开花至成熟 阶段 0 100 cm 土层供水能力提高; 相同补灌水平不 同补灌时期各处理的土壤咜水消耗量比较, $0 \sim 80 \mathrm{~cm}$ 土层为 $\mathrm{W} 5>\mathrm{W} 2, \mathrm{~W} 6>\mathrm{W} 3,80 \sim 120 \mathrm{~cm}$ 土层为 $\mathrm{W} 2>\mathrm{W} 5$, $\mathrm{W} 3>\mathrm{W} 6$ (图 1), 说明与拔节期补灌相比, 拔节后 $10 \mathrm{~d}$ 补灌提高了开花至成熟阶段 $0 \sim 80 \mathrm{~cm}$ 土层土壤䛎水 消耗量, 降低了 80 120 cm 土层土壤财水消耗量。

2008-2009 生长季, 拔节至开花阶段小麦主要 利用 $0 \sim 120 \mathrm{~cm}$ 土层的水分, $\mathrm{W} 2$ 处理 $0 \sim 80 \mathrm{~cm}$ 土层土 
壤咜水消耗量低于 $\mathrm{W} 1$ 处理, $80 \sim 120 \mathrm{~cm}$ 土层土壤咜 水消耗量高于 $\mathrm{W} 1$ 处理; 开花至成熟阶段, W2 处理 0 80 cm 土层土壤㲸水消耗量高于 $\mathrm{W} 1$ 处理, 80 140 $\mathrm{cm}$ 土层土壤咜水消耗量低于 $\mathrm{W} 1$ 处理(图 2), 说明拔 节后 $10 \mathrm{~d}$ 补灌拔节水增加了拔节期根系对 80 120 $\mathrm{cm}$ 土层水分的吸收, 提高了开花至成熟阶段 $0 \sim 80$ $\mathrm{cm}$ 土层根系的吸收能力。

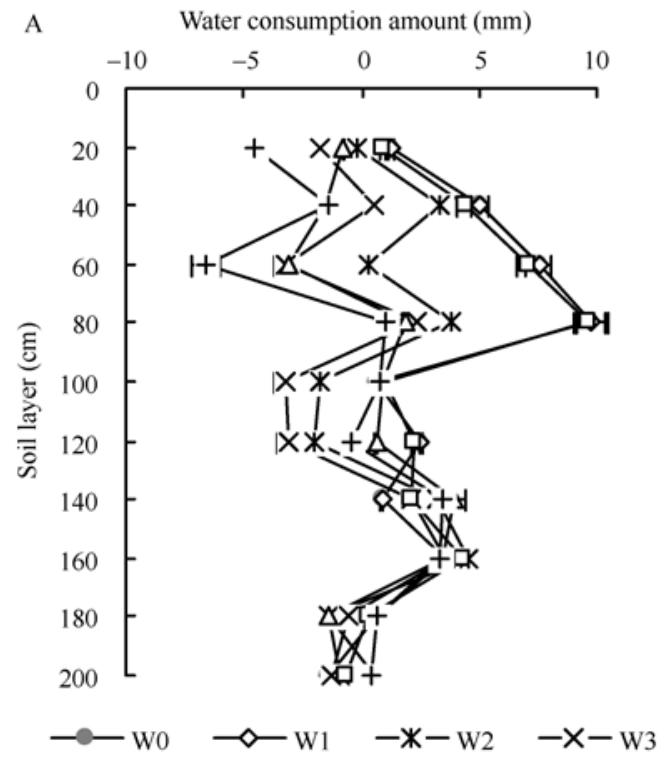

2.2 不同处理对小麦不同生育阶段日耗水量的 影响

2007-2008 生长季小麦日耗水量为播种至拔节 阶段最小, 随生育进程逐渐增大, 开花至成熟阶段 最大; $\mathrm{W} 0$ 处理拔节至成熟阶段日耗水量显著低于灌 水处理; 相同补灌时期的日耗水量, 拔节至开花阶 段表现为 $\mathrm{W} 3>\mathrm{W} 2>\mathrm{W} 1$, 拔节后 $10 \mathrm{~d}$ 至开花阶段为

B

Water consumption amount $(\mathrm{mm})$

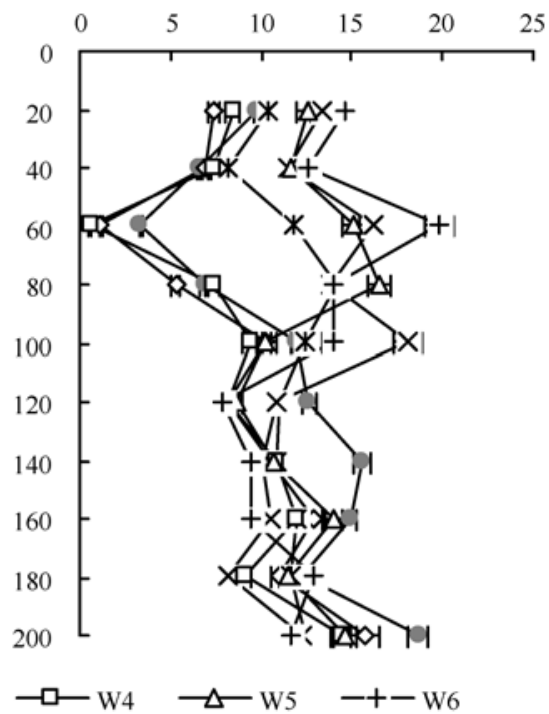

图 1 各生育阶段不同土层耗水量(2007-2008)

Fig. 1 Soil water consumption amount in various soil layers at different growth stages (2007-2008)

A：拔节至开花; B: 开花至成熟。W0：不灌水; W1、W2 和 W3: 拔节期灌水; W4、W5 和 W6: 拔节后 10 d 灌水。

A: from jointing stage to flowering stage; B: from flowering stage to maturity stage. W0: no irrigation; W1, W2, and W3: irrigated at jointing stage; W4, W5, and W6: irrigated at $10 \mathrm{~d}$ after jointing stage.
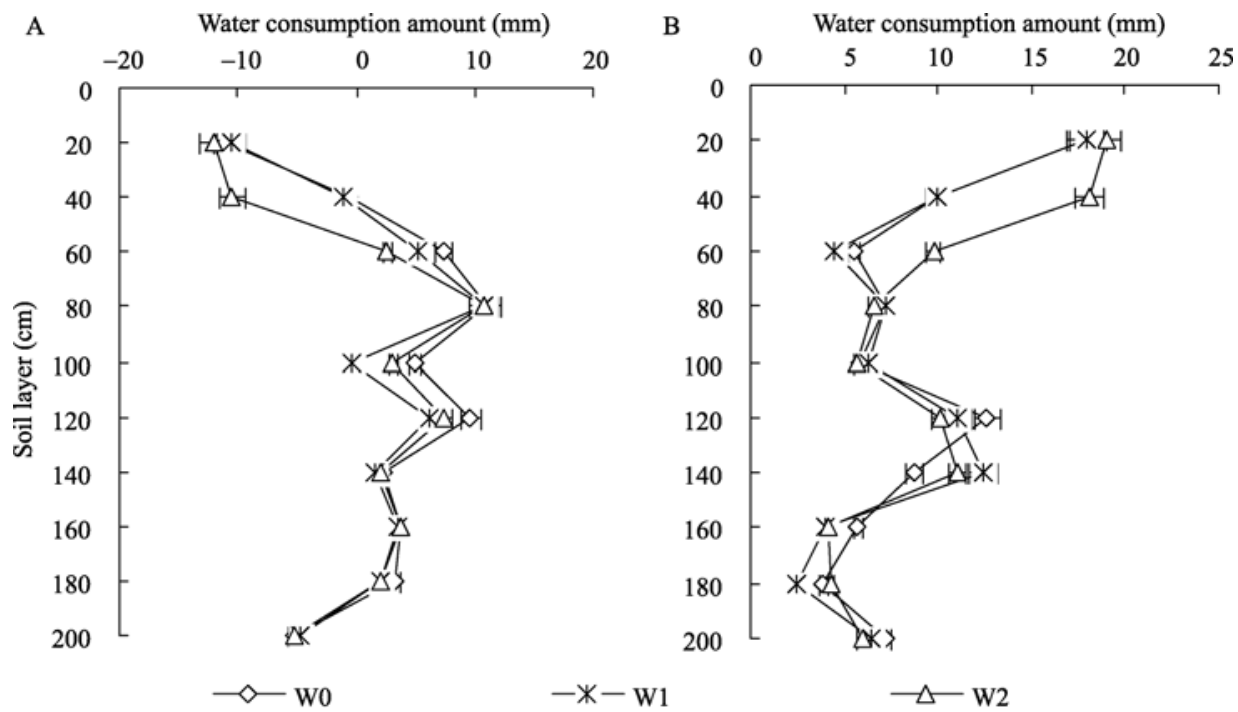

图 2 各生育阶段不同土层耗水量(2008-2009)

Fig. 2 Soil water consumption amount in various soil layers at different growth stages (2008-2009)

A：拔节至开花; B：开花至成熟。W0：不灌水; W1：拔节期灌水; W2：拔节后 $10 \mathrm{~d}$ 灌水。

A: from jointing stage to flowering stage; B: from flowering stage to maturity stage. W0: no irrigation; W1: irrigated at jointing stage; W2: irrigated at $10 \mathrm{~d}$ after jointing stage. 
W6>W5 $>$ W4，开花至成熟阶段差异不显著(图 3)，说 明随拔节期补灌水平提高, 拔节至开花阶段小麦日 耗水量增大; 相同补灌水平不同补灌时期的日耗水 量, 拔节至拔节后 $10 \mathrm{~d}$ 为 $\mathrm{W} 1>\mathrm{W} 4, \mathrm{~W} 2>\mathrm{W} 5, \mathrm{~W} 3>$ $\mathrm{W} 6$, 拔节后 $10 \mathrm{~d}$ 至开花阶段为 $\mathrm{W} 4>\mathrm{W} 1, \mathrm{~W} 5>\mathrm{W} 2$, $\mathrm{W} 6>\mathrm{W} 3$ (图 3), 说明拔节后 $10 \mathrm{~d}$ 补灌拔节水显著降 低拔节至拔节后 $10 \mathrm{~d}$ 的小麦日耗水量, 提高了拔节 后 $10 \mathrm{~d}$ 至开花阶段的日耗水量, 有利于促进拔节初 期分㒘的两极分化和保证挑旗期的水分需求。

2008-2009 生长季小麦日耗水量为开花至成熟

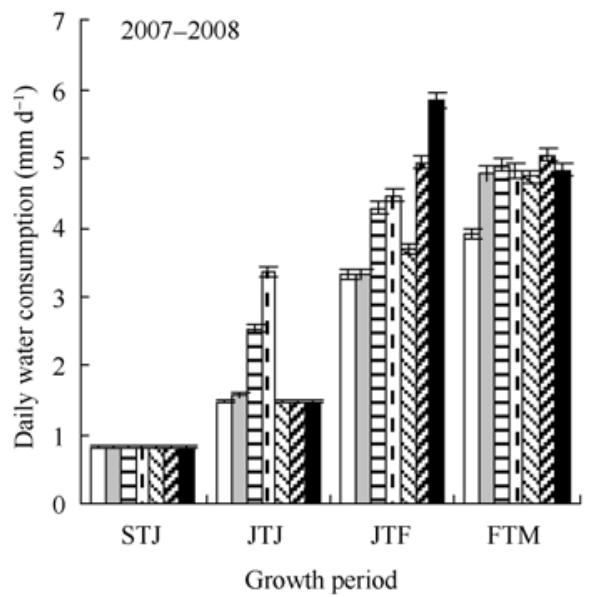

$\square \mathrm{W} 0 \quad \square \mathrm{W} 1 \quad \square \mathrm{W} 2 \square \mathrm{W} 3 \quad \mathrm{~W} 4 \quad \mathrm{~W} 5 \quad \mathbf{W} 6$

阶段最大，播种至拔节阶段最小; W0 处理拔节至成 熟阶段小麦日耗水量显著低于灌水处理; W2 处理拔 节至拔节后 $10 \mathrm{~d}$ 的日耗水量显著低于 $\mathrm{W} 1$ 处理, 拔 节后 $10 \mathrm{~d}$ 至开花阶段则显著高于 $\mathrm{W} 1$ 处理, 开花至 成熟阶段差异不显著(图 3), 说明将补灌时期后延至 拔节后 $10 \mathrm{~d}$ 增加了挑旗期的日耗水量。

2.3 不同处理对灌浆初期单位土地面积上旗叶 叶面积和蒸腾速率及株间蒸发量的影响

W0 处理灌浆初期单位土地面积上旗叶叶面积 和蒸腾速率最小，株间蒸发量最大(图 4); 相同补灌

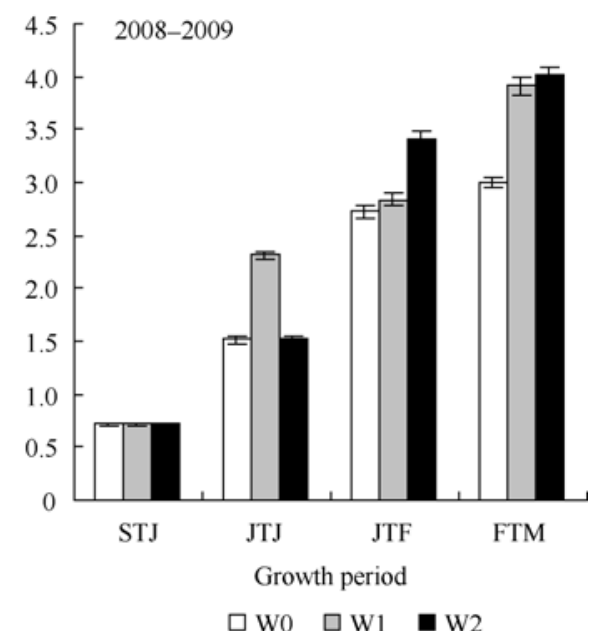

图 3 不同处理各生育阶段日耗水量

Fig. 3 Daily water consumption of different treatments at various growth stages

STJ：播种至拔节; JTJ：拔节至拔节后 $10 \mathrm{~d}$; JTF：拔节后 $10 \mathrm{~d}$ 至开花; FTM：开花至成熟。2007-2008 年度, W0：不灌水; W1、W2 和 W3: 拔节期灌水; W4、W5 和 W6: 拔节后 $10 \mathrm{~d}$ 灌水。2008-2009 年度, W0: 不灌水; W1: 拔节期灌水; W2: 拔节后 $10 \mathrm{~d}$ 灌水。 STJ: from sowing to jointing; JTJ: from jointing to $10 \mathrm{~d}$ after jointing; JTF: from $10 \mathrm{~d}$ after jointing to flowering; FTM: from flowering to maturiy. In 2007-2008 growing season, W0: no irrigation; W1, W2, and W3: irrigated at jointing stage; W4, W5, and W6: irrigated at $10 \mathrm{~d}$ after jointing. In 2008-2009 growing season, W0: no irrigation; W1: irrigated at jointing stage; W2: irrigated at $10 \mathrm{~d}$ after jointing.

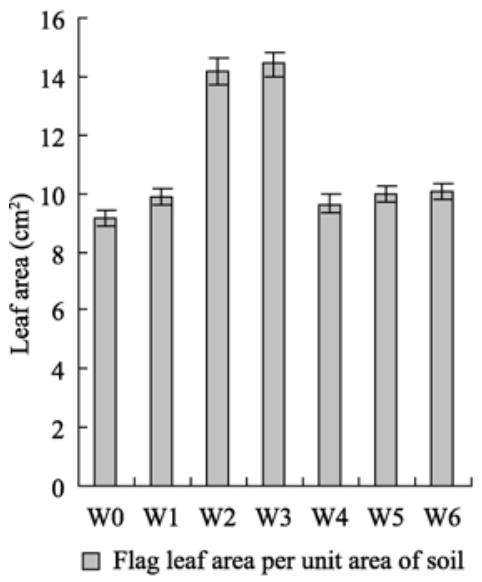

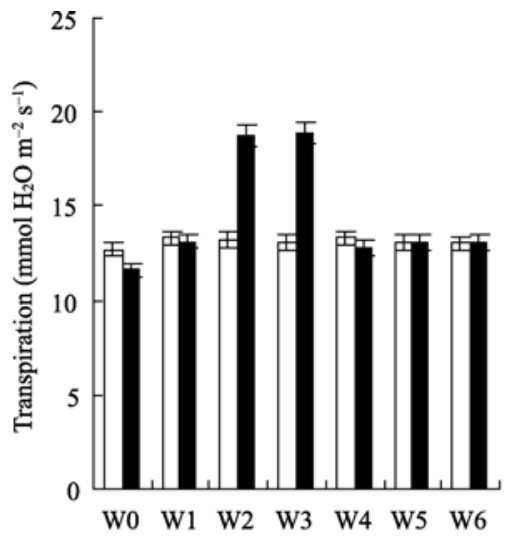

$\square$ Flag leaf transpiration

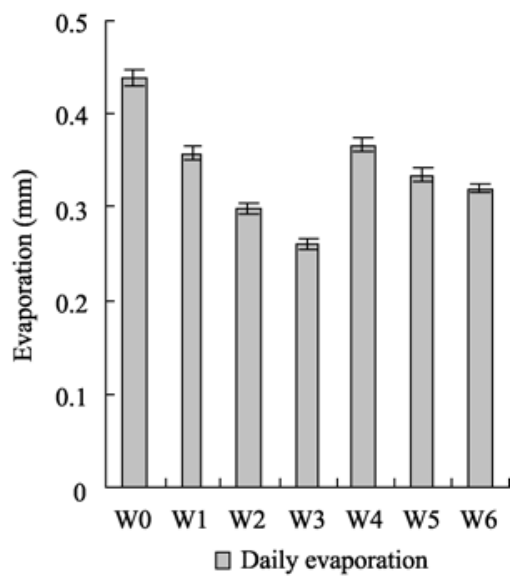

$\square$ Daily evaporation

图 4 灌浆初期单位土地面积上旗叶叶面积和蒸腾速率及株间蒸发量(2007-2008)

Fig. 4 Flag leaf area per unit area of soil, transpiration per unit area of soil , and soil evaporation at early filling stage (2007-2008) W0: 不灌水; W1、W2 和 W3: 拔节期灌水; W4、W5 和 W6: 拔节后 $10 \mathrm{~d}$ 灌水。 W0: no irrigation; W1, W2, and W3: irrigated at jointing stage; W4, W5, and W6: irrigated at $10 \mathrm{~d}$ after jointing. 
时期各处理的株间蒸发量为 $\mathrm{W} 1>\mathrm{W} 2>\mathrm{W} 3, \mathrm{~W} 4>\mathrm{W} 5>$ W6, 单位土地面积上旗叶叶面积和蒸腾速率为 $\mathrm{W} 2 、 \mathrm{~W} 3>\mathrm{W} 1$, 而 W4、W5 和 W6 处理间差异不显 著(图 4), 说明随拔节期补灌水平的提高, 灌浆初期 单位土地面积上旗叶面积和蒸腾速率逐渐增大, 株 间蒸发量逐渐降低, 随拔节后 $10 \mathrm{~d}$ 补灌水平提高, 灌浆初期单位土地面积上旗叶叶面积和蒸腾速率差 异不显著, 株间蒸发量逐渐降低; 相同补灌水平不 同补灌时期的株间蒸发量为 W5 $>$ W 2, W6 $>$ W3, 单位 土地面积上旗叶叶面积和蒸腾速率表现为 W2 $>\mathrm{W} 5$, W3 > W6 (图 4), 说明拔节后 $10 \mathrm{~d}$ 补灌增加了灌浆初 期株间蒸发量, 降低了单位土地面积上旗叶叶面积 和旗叶蒸腾速率。

2.4 不同处理对田间耗水的水分来源及其占田 间耗水量百分率的影响

2007-2008 生长季, W0 处理田间耗水量最低, 土壤咜水消耗量及其占田间耗水量的比例最高(表 2); 相同补灌时期不同补灌水平的各处理间比较, 田间耗水量、灌水量及其占田间耗水量的比例为 $\mathrm{W} 3>\mathrm{W} 2>\mathrm{W} 1, \mathrm{~W} 6>\mathrm{W} 5>\mathrm{W} 4$, 土壤咜水消耗量为 $\mathrm{W} 2>$ $\mathrm{W} 1$ 和 $\mathrm{W} 3, \mathrm{~W} 5>\mathrm{W} 6>\mathrm{W} 4$, 土壤耗水量和降水量占田 间耗水量的比例为 $\mathrm{W} 1>\mathrm{W} 2>\mathrm{W} 3, \mathrm{~W} 4>\mathrm{W} 5>\mathrm{W} 6$ (表 2), 说明随拔节期补灌水平的提高, 田间耗水量、灌水
量及其占田间耗水量的比例升高，土壤䛎水消耗量 先升高后降低, 土壤咜水消耗量和降水量占田间耗 水量的比例降低; 相同补灌水平不同补灌时期的各 处理间比较, 灌水量为 $\mathrm{W} 4>\mathrm{W} 1, \mathrm{~W} 5>\mathrm{W} 2, \mathrm{~W} 6>\mathrm{W} 3$, 土壤咜水消耗量为 $\mathrm{W} 5>\mathrm{W} 2, \mathrm{~W} 1$ 和 $\mathrm{W} 4$ 以及 $\mathrm{W} 3$ 和 W6 之间差异不显著, 田间耗水量为 W5>W2, W6> W3, 但降水量、灌水量和土壤咜水消耗量占田间耗 水量的比例差异均不显著(表 2), 说明拔节后 $10 \mathrm{~d}$ 补 灌没有改变各水分来源占田间耗水量的百分率。

2008-2009 生长季 W0 处理田间耗水量最低, 土壤咜水消耗量和降水量占田间耗水量的比例最高; $\mathrm{W} 2$ 处理灌水量和田间耗水量高于 $\mathrm{W} 1$ 处理, 土壤䞎 水消耗量、降水量、灌水量和土壤䛎水消耗量占田 间耗水量的比例两处理差异均不显著(表 2), 说明拔 节后 $10 \mathrm{~d}$ 补灌的水量增加，但各水分来源占田间耗 水量的百分率不变。2008-2009 与 2007-2008 生长 季试验结果一致。

2.5 不同处理对小麦籽粒产量、产量构成因素和 水分利用效率的影响

2007-2008 生长季, W0 处理穗数、穗粒数和籽 粒产量均显著低于各灌水处理(表 3); 相同补灌时期 不同补灌水平的各处理间比较, W2 和 W3 处理的穗 数、穗粒数和籽粒产量显著高于 W1 处理, W5 和 W6

表 2 不同处理对田间耗水量的水分来源及其占田间耗水量的百分率的影响

Table 2 Effects of different treatments on water consumption resources and the ratio of different water resources to water consumption amount

\begin{tabular}{|c|c|c|c|c|c|c|c|}
\hline \multirow{2}{*}{$\begin{array}{c}\text { 处理 } \\
\text { Treatment }\end{array}$} & \multirow{2}{*}{$\begin{array}{c}\text { 田间耗水量 } \\
\text { Water consump- } \\
\text { tion (mm) }\end{array}$} & \multicolumn{2}{|c|}{ 降水 Precipitation } & \multicolumn{2}{|c|}{ 灌水 Irrigation } & \multicolumn{2}{|c|}{ 土壤咜水消耗 Soil water consumption } \\
\hline & & $\begin{array}{c}\text { 总量 } \\
\text { Amount (mm) }\end{array}$ & $\begin{array}{c}\text { 百分率 } \\
\text { Percentage }(\%)\end{array}$ & $\begin{array}{c}\text { 总量 } \\
\text { Amount (mm) }\end{array}$ & $\begin{array}{c}\text { 百分率 } \\
\text { Percentage }(\%)\end{array}$ & $\begin{array}{c}\text { 消耗量 } \\
\text { Amount (mm) }\end{array}$ & $\begin{array}{c}\text { 百分率 } \\
\text { Percentage (\%) }\end{array}$ \\
\hline \multicolumn{8}{|l|}{ 2007-2008 } \\
\hline W0 & $381.4 \pm 2.7 \mathrm{e}$ & 141.7 & $37.2 \pm 0.5 \mathrm{a}$ & - & - & $239.7 \pm 1.7 \mathrm{a}$ & $62.9 \pm 0.9 \mathrm{a}$ \\
\hline W1 & $414.5 \pm 2.9 \mathrm{~d}$ & 141.7 & $34.2 \pm 0.5 \mathrm{~b}$ & 56.3 & $13.6 \pm 0.4 \mathrm{c}$ & $216.5 \pm 1.5 \mathrm{de}$ & $52.2 \pm 0.7 \mathrm{~b}$ \\
\hline W2 & $450.3 \pm 3.2 \mathrm{c}$ & 141.7 & $31.5 \pm 0.5 \mathrm{c}$ & 88.3 & $19.6 \pm 0.6 \mathrm{~b}$ & $220.2 \pm 1.6 \mathrm{c}$ & $48.9 \pm 0.7 \mathrm{c}$ \\
\hline W3 & $460.8 \pm 3.3 \mathrm{~b}$ & 141.7 & $30.8 \pm 0.4 \mathrm{~cd}$ & 102.4 & $22.2 \pm 0.6 \mathrm{a}$ & $216.8 \pm 1.5 \mathrm{cde}$ & $47.0 \pm 0.7 \mathrm{~d}$ \\
\hline W4 & $419.6 \pm 3.0 \mathrm{~d}$ & 141.7 & $33.8 \pm 0.5 \mathrm{~b}$ & 62.0 & $14.8 \pm 0.4 \mathrm{c}$ & $215.9 \pm 1.5 \mathrm{e}$ & $51.5 \pm 0.7 \mathrm{~b}$ \\
\hline W5 & $457.6 \pm 3.2 \mathrm{~b}$ & 141.7 & $31.0 \pm 0.5 \mathrm{~cd}$ & 89.5 & $19.6 \pm 0.6 b$ & $226.4 \pm 1.6 \mathrm{~b}$ & $49.5 \pm 0.7 \mathrm{c}$ \\
\hline W6 & $468.3 \pm 3.3 \mathrm{a}$ & 141.7 & $30.3 \pm 0.4 \mathrm{~d}$ & 106.9 & $22.8 \pm 0.7 \mathrm{a}$ & $219.7 \pm 1.6 \mathrm{~cd}$ & $46.9 \pm 0.7 \mathrm{~d}$ \\
\hline \multicolumn{8}{|l|}{$2008-2009$} \\
\hline W0 & $316.2 \pm 2.2 \mathrm{c}$ & 140.4 & $44.4 \pm 0.6 \mathrm{a}$ & - & - & $175.8 \pm 1.2 \mathrm{a}$ & $55.6 \pm 0.8 \mathrm{a}$ \\
\hline W1 & $360.6 \pm 2.6 \mathrm{~b}$ & 140.4 & $38.9 \pm 0.6 \mathrm{~b}$ & 59.34 & $16.5 \pm 0.5 \mathrm{a}$ & $160.9 \pm 1.1 \mathrm{~b}$ & $44.6 \pm 0.6 \mathrm{~b}$ \\
\hline W2 & $370.1 \pm 2.6 \mathrm{a}$ & 140.4 & $37.9 \pm 0.5 \mathrm{~b}$ & 65.48 & $17.7 \pm 0.5 \mathrm{a}$ & $164.2 \pm 1.2 \mathrm{~b}$ & $44.4 \pm 0.6 \mathrm{~b}$ \\
\hline
\end{tabular}

2007-2008 年度, W0: 不灌水; W1、W2 和 W3：拔节期灌水; W4、W5 和 W6: 拔节后 $10 \mathrm{~d}$ 灌水。2008-2009 年度, W0: 不灌水; W1： 拔节期灌水; W2: 拔节后 $10 \mathrm{~d}$ 灌水。数据后相同字母表示该年度中处理间无显著差异 $(P<0.05)$ 。

In 2007-2008 growing season, W0: no irrigation; W1, W2, and W3: irrigated at jointing stage; W4, W5, and W6: irrigated at 10 d after jointing. In 2008-2009 growing season, W0: no irrigation; W1: irrigated at jointing stage; W2: irrigated at $10 \mathrm{~d}$ after jointing. In each growing season, values followed by the same letter are not significantly different between treatments $(P<0.05)$ 
表 3 不同处理对小麦产量及其构成因素和水分利用效率的影响

Table 3 Effect of irrigation treatments on yield and its components and water use efficiency in wheat

\begin{tabular}{|c|c|c|c|c|c|c|}
\hline $\begin{array}{c}\text { 处理 } \\
\text { Treatment }\end{array}$ & $\begin{array}{c}\text { 穗数 } \\
\text { Spike number } \\
\left(\times 10^{4} \mathrm{hm}^{-2}\right)\end{array}$ & $\begin{array}{l}\text { 穗粒数 } \\
\text { Grain number per } \\
\text { spike }\end{array}$ & $\begin{array}{c}\text { 千粒重 } \\
\text { 1000-grain weight } \\
\text { (g) }\end{array}$ & $\begin{array}{c}\text { 籽粒产量 } \\
\text { Grain yield } \\
\left(\mathrm{kg} \mathrm{hm}^{-2}\right)\end{array}$ & $\begin{array}{c}\text { 产量水分利用效率 } \\
\text { Water use efficiency } \\
\quad\left(\mathrm{kg} \mathrm{hm}^{-2} \mathrm{~mm}^{-1}\right)\end{array}$ & $\begin{array}{c}\text { 灌水生产效率 } \\
\text { IPE } \\
\left(\mathrm{kg} \mathrm{hm}^{-2} \mathrm{~mm}^{-1}\right)\end{array}$ \\
\hline \multicolumn{7}{|l|}{ 2007-2008 } \\
\hline W0 & $640.0 \pm 9.1 \mathrm{c}$ & $31.3 \pm 0.4 \mathrm{~d}$ & $40.4 \pm 0.6 \mathrm{ab}$ & $7896.3 \pm 55.8 \mathrm{~d}$ & $20.7 \pm 0.2 b$ & - \\
\hline W1 & $668.7 \pm 9.5 \mathrm{~b}$ & $34.2 \pm 0.5 \mathrm{c}$ & $40.9 \pm 0.6 \mathrm{ab}$ & $8750.4 \pm 61.9 \mathrm{c}$ & $21.1 \pm 0.2 \mathrm{a}$ & $15.2 \pm 0.3 \mathrm{~b}$ \\
\hline W2 & $711.7 \pm 10.1 \mathrm{a}$ & $36.2 \pm 0.5 \mathrm{~b}$ & $40.4 \pm 0.6 \mathrm{ab}$ & $9041.7 \pm 63.9 \mathrm{~b}$ & $20.1 \pm 0.1 \mathrm{c}$ & $13.0 \pm 0.3 \mathrm{~d}$ \\
\hline W3 & $723.0 \pm 10.2 \mathrm{a}$ & $36.1 \pm 0.5 \mathrm{~b}$ & $40.0 \pm 0.6 \mathrm{~b}$ & $9029.8 \pm 63.9 \mathrm{~b}$ & $19.6 \pm 0.1 \mathrm{~d}$ & $11.1 \pm 0.2 \mathrm{e}$ \\
\hline W4 & $666.7 \pm 9.4 \mathrm{~b}$ & $34.2 \pm 0.5 \mathrm{c}$ & $41.1 \pm 0.6 \mathrm{ab}$ & $8836.8 \pm 62.5 \mathrm{c}$ & $21.1 \pm 0.2 \mathrm{a}$ & $15.2 \pm 0.3 \mathrm{~b}$ \\
\hline W5 & $679.4 \pm 9.6 \mathrm{~b}$ & $39.3 \pm 0.6 \mathrm{a}$ & $41.6 \pm 0.6 \mathrm{a}$ & $9378.6 \pm 66.3 \mathrm{a}$ & $20.5 \pm 0.1 \mathrm{~b}$ & $16.6 \pm 0.4 \mathrm{a}$ \\
\hline W6 & $687.4 \pm 9.7 \mathrm{~b}$ & $39.2 \pm 0.6 \mathrm{a}$ & $41.3 \pm 0.6 \mathrm{ab}$ & $9400.8 \pm 66.5 \mathrm{a}$ & $20.1 \pm 0.1 \mathrm{c}$ & $14.1 \pm 0.3 \mathrm{c}$ \\
\hline \multicolumn{7}{|l|}{$2008-2009$} \\
\hline W0 & $558.5 \pm 4.0 \mathrm{c}$ & $31.0 \pm 0.4 \mathrm{c}$ & $40.9 \pm 0.6 \mathrm{a}$ & $6704.6 \pm 47.4 \mathrm{c}$ & $21.2 \pm 0.2 \mathrm{c}$ & - \\
\hline W1 & $645.0 \pm 4.6 \mathrm{a}$ & $35.4 \pm 0.5 \mathrm{~b}$ & $40.6 \pm 0.6 \mathrm{a}$ & $7902.7 \pm 55.9 \mathrm{~b}$ & $21.9 \pm 0.2 \mathrm{~b}$ & $20.2 \pm 0.4 \mathrm{~b}$ \\
\hline W2 & $628.0 \pm 4.4 \mathrm{~b}$ & $38.4 \pm 0.5 \mathrm{a}$ & $40.6 \pm 0.6 \mathrm{a}$ & $8437.2 \pm 59.7 \mathrm{a}$ & $22.8 \pm 0.2 \mathrm{a}$ & $26.5 \pm 0.6 \mathrm{a}$ \\
\hline
\end{tabular}

2007-2008 年度, W0：不灌水; W1、W2 和 W3：拔节期灌水; W4、W5 和 W6: 拔节后 $10 \mathrm{~d}$ 灌水。2008-2009 年度, W0: 不灌水; W1: 拔节期灌水; W2: 拔节后 $10 \mathrm{~d}$ 灌水。数据后相同字母表示该年度中处理间无显著差异 $(P<0.05)$ 。

In 2007-2008 growing season, W0: no irrigation; W1, W2, and W3: irrigated at jointing stage; W4, W5, and W6: irrigated at $10 \mathrm{~d}$ after jointing. In 2008-2009 growing season, W0: no irrigation; W1: irrigated at jointing stage; W2: irrigated at $10 \mathrm{~d}$ after jointing. In each growing season, values followed by the same letter are not significantly different between treatments $(P<0.05)$. IPE: irrigation production efficiency.

处理穗粒数和产量显著高于 W4 处理, 水分利用效 率 $\mathrm{W} 1$ 和 $\mathrm{W} 4$ 处理最大, $\mathrm{W} 3$ 和 $\mathrm{W} 6$ 处理最小, 灌水 生产效率 W5 处理最大, W3 处理最小(表 3), 说明拔 节期补灌水平最低的 $\mathrm{W} 1$ 和 $\mathrm{W} 4$ 处理显著降低了穗 粒数和产量, 拔节期补灌水平最高的 $\mathrm{W} 3$ 和 $\mathrm{W} 6$ 处理 显著降低了水分利用效率和灌水生产效率, $\mathrm{W} 2$ 和 W5 处理的产量、水分利用效率和灌水生产效率均较 高, 均为相同补灌时期的最优处理; 相同补灌水平 不同补灌时期的各处理间比较, W5 和 W6 处理的穗 数分别低于 $\mathrm{W} 2$ 和 $\mathrm{W} 3$ 处理, 穗粒数、千粒重、籽粒 产量、水分利用效率和灌水生产效率分别高于 W2 和 $\mathrm{W} 3$ 处理(表 3), 说明拔节后 $10 \mathrm{~d}$ 补灌降低了穗数, 但提高了穗粒数和千粒重, 从而提高了籽粒产量、 水分利用效率和灌水生产效率。

2008-2009 生长季 W0 处理的穗数、穗粒数、 籽粒产量和水分利用效率均显著低于灌水处理; 拔 节后 $10 \mathrm{~d}$ 补灌的 $\mathrm{W} 2$ 处理穗数低于拔节期灌水的 W1 处理, 而穗粒数、籽粒产量、水分利用效率和灌 水生产效率高于 $\mathrm{W} 1$ 处理, 两处理千粒重差异不显 著(表 3), 说明拔节后 $10 \mathrm{~d}$ 补灌能满足挑旗孕穗期的 水分需求, 减少小花的退化, 增加穗粒数, 从而提 高杼粒产量、水分利用效率和灌水生产效率。

\section{3 讨论}

围绕减少农作物的灌溉次数和灌水量已开展过
较多研究。刘彦军 ${ }^{[13]}$ 提出冬小麦以春灌 3 水最佳, 每 次灌水量 $75 \mathrm{~mm}$, 在生育期降水量 $159 \mathrm{~mm}$ 条件下, 籽粒产量达 $8101.5 \mathrm{~kg} \mathrm{hm}^{-2}$, 水分利用效率为 16.1 $\mathrm{kg} \mathrm{hm}^{-2} \mathrm{~mm}^{-1}$ 。张忠学和吴文良 ${ }^{[14]}$ 在华北高产粮区 的研究表明, 最佳灌水模式为春灌 2 水, 每次 $75 \mathrm{~mm}$, 在生育期降水量 $111.4 \mathrm{~mm}$ 条件下, 冬小麦籽粒产量 为 $7716.7 \mathrm{~kg} \mathrm{hm}^{-2}$, 水分利用效率为 $15.9 \mathrm{~kg} \mathrm{~h}^{-2}$ $\mathrm{mm}^{-1}$ 。刘庚山等 ${ }^{[15]}$ 通过人工控制有限供水, 在拔节 期一次性供水 $75 \mathrm{~mm}$, 结果籽粒产量仅为 $4045.4 \mathrm{~kg}$ $\mathrm{hm}^{-2}$, 水分利用效率为 $14.2 \mathrm{~kg} \mathrm{~h}^{-2} \mathrm{~mm}^{-1}$ 。本试验在 前人研究基础上确定春灌拔节水和开花水, 灌水量 通过灌水前测定土壤墑情来确定, 在 2007-2008 生 长季(小麦生育期降水量 $141.7 \mathrm{~mm}$ )的 6 个处理中灌 水量最低为 $56.3 \mathrm{~mm}$, 最高为 $106.9 \mathrm{~mm}$, 籽粒产量 最低为 $8750.4 \mathrm{~kg} \mathrm{~h}^{-2}$, 最高为 $9400.8 \mathrm{~kg} \mathrm{hm}^{-2}$, 水 分利用效率最低为 $19.6 \mathrm{~kg} \mathrm{hm}^{-2} \mathrm{~mm}^{-1}$, 最高为 21.1 $\mathrm{kg} \mathrm{hm}^{-2} \mathrm{~mm}^{-1} ; 2008$-2009 生长季(小麦生育期降水 量 $140.4 \mathrm{~mm}) \mathrm{W} 1$ 和 $\mathrm{W} 2$ 处理总灌水量分别为 59.3 $\mathrm{mm}$ 和 $65.5 \mathrm{~mm}$, 杼粒产量分别为 $7902.7 \mathrm{~kg} \mathrm{hm}^{-2}$ 和 $8437.2 \mathrm{~kg} \mathrm{hm}^{-2}$, 水分利用率为 $21.9 \mathrm{~kg} \mathrm{hm}^{-2} \mathrm{~mm}^{-1}$ 和 $22.8 \mathrm{~kg} \mathrm{hm}^{-2} \mathrm{~mm}^{-1}$ 。两生长季降水量均在 $140 \mathrm{~mm}$ 左 右, 总灌水量最高为 $106.9 \mathrm{~mm}$, 小麦产量达 $7900.0 \sim$ $9400.8 \mathrm{~kg} \mathrm{hm}^{-2}$, 水分利用率为 $19.6 \sim 22.8 \mathrm{~kg} \mathrm{hm}^{-2}$ $\mathrm{mm}^{-1}$, 说明测墑补灌能在节水条件下实现高产和高 水分利用率的目标。 
冬小麦耗水量与产量呈二次抛物线函数关系 ${ }^{[16]}$, 在中等干旱条件下小麦耗水量大幅下降，而产量的 降幅较小, 有利于水分利用效率的提高 ${ }^{[17-20]}$ 。也有 研究认为, 适度水分亏缺可以同时提高作物产量和 水分利用效率 ${ }^{[21-23]}$, 但水分逆境显著降低了小麦粒 重和产量 ${ }^{[24]}$ 。在本试验中, 2007-2008 生长季拔节 期灌水的 3 个处理中以 $\mathrm{W} 3$ 处理耗水量最大, 并且籽 粒产量和水分利用效率均低于 W2 处理, 在拔节后 $10 \mathrm{~d}$ 灌水的 3 个处理中以 $\mathrm{W} 6$ 处理耗水量最大, W5 和 W6 处理的产量无差异, 但 W5 处理水分利用效率 和灌水生产效率显著高于 $\mathrm{W} 6$ 。相同补灌水平不同补 灌时期的处理间比较, W5 和 W6 处理籽粒产量、水 分利用效率和灌水生产效率均显著高于 W2 和 W3, W5 处理耗水量仅比 W2 处理多 $7.3 \mathrm{~mm}$, 但产量高 $336.9 \mathrm{~kg} \mathrm{hm}^{-2}$, 灌水生产效率高 $3.6 \mathrm{~kg} \mathrm{hm}^{-2} \mathrm{~mm}^{-1}$, 说明随着补灌水平的提高, 籽粒产量上升变缓, 甚 至出现下降, 由拔节期推迟至拔节后 $10 \mathrm{~d}$ 补灌拔节 水能显著提高籽粒产量、水分利用效率和灌水生产 效率。

土壤咜水是冬小麦水分的重要来源 ${ }^{[25]}$, 随灌水 量的增加, 冬小麦总耗水量也增加, 土壤咜水特别 是深层咜水消耗量相应减少 ${ }^{[26-28]}$, 土壤咜水消耗量 占总耗水量的比例降低 ${ }^{[29-30]}$ 。本试验结果表明, 相 同补灌时期的各处理随补灌水平提高, 拔节至开花 阶段 $0 \sim 120 \mathrm{~cm}$ 土层土壤咜水消耗量显著降低, 全生 育期灌水量和总耗水量增加, 土壤䛎水消耗量和降 雨量占总耗水量的比例降低。W0 处理土壤咜水消耗 量最大, 总耗水量最小, 灌水处理中 $\mathrm{W} 1$ 和 $\mathrm{W} 4$ 处理 灌水量和总耗水量最小, 土壤咜水消耗量占总耗水 量的比例最大, $\mathrm{W} 3$ 和 $\mathrm{W} 6$ 处理土壤䛎水消耗量占总 耗水量的比例最小。相同补灌水平不同补灌时期的 处理间比较, W4、W5 和 W6 处理拔节至开花阶段 80 120 cm 土层土壤咜水消耗量分别大于 $\mathrm{W} 1$ 、 W2 和 $\mathrm{W} 3$ 处理, 全生育期灌水量和总耗水量亦如此, 但 全生育期土壤咜水消耗量及其占总耗水量的比例并 没有减小, 说明由拔节期延迟至拔节后 $10 \mathrm{~d}$ 补灌拔 节水, 虽然增加了灌水量和总耗水量, 但同时增加 了土壤䛎水消耗量, 故并未降低土壤䛎水消耗量占 总耗水量的比例。

有研究指出, 株间蒸发主要受表层 $(0 \sim 10 \mathrm{~cm})$ 土 壤水分控制, 随着土壤表层含水量的减少, 蒸发速 度降低, 随着叶面积指数的增加, 株间蒸发量减少, 因此不同灌水处理蒸发强度的差异一般只出现在灌 水和降水后的几天之内, 其他时段内的差异很小或
无显著差异 ${ }^{[31]}$ 。小麦的蒸腾速率随光照强度增加而 增加 ${ }^{[32]}$, 当光合有效辐射超过 $1000 \mu \mathrm{mol} \mathrm{m}^{-2} \mathrm{~s}^{-1}$ 时, 光合速率随光合有效辐射的增加而下降，蒸腾量依 然呈线性增加, 超出此临界值的蒸腾为奢侈蒸腾, 通过合适的调控措施，降低这部分蒸腾并不影响光 合生产 ${ }^{[33]}$ 。在本试验中, 所有灌水处理开花期均灌 水至同一水平，灌浆初期株间蒸发测定前刚降雨 $29.5 \mathrm{~mm}$, 故所有处理土壤表层含水量相差较小。拔 节期随补灌水平的提高, 灌浆初期单位土地面积上 旗叶叶面积增大，株间蒸发量减少，单叶旗叶蒸腾 速率无显著差异, 但单位土地面积上旗叶蒸腾速率 增大; 随拔节后 $10 \mathrm{~d}$ 补灌水平提高, 灌浆初期单位 土地面积上旗叶叶面积和蒸腾速率差异不显著, 株 间蒸发量降低但差异较小。与拔节期补灌相比，拔 节后 $10 \mathrm{~d}$ 补灌增加了灌浆初期株间蒸发量, 降低了 单位土地面积上旗叶叶面积和蒸腾速率。

本试验两年降雨量相近，在其他降雨年型下的 适宜补灌时期和补灌水平有待进一步研究。

\section{4 结论}

测墒补灌能在节水条件下实现高产和高水分利 用率的目标。与拔节期补灌相比，拔节后 $10 \mathrm{~d}$ 补灌 在不降低降水量和土壤咜水消耗量所占总耗水量的 比例的情况下显著提高籽粒产量、水分利用效率和 灌水生产效率。拔节后 $10 \mathrm{~d}$ 补灌至 0 140 $\mathrm{cm}$ 土层 土壤相对含水量的 75\%、开花期补灌至 70\%的处理 获得较高的籽粒产量和水分利用效率，灌水生产效 率最高，是适合本试验条件(2007-2008)的高产节 水的最佳灌溉方案。

\section{References}

[1] Kang S-Z(康绍忠), Hu X-T(胡笑涛), Cai H-J(蔡焕杰), Feng S-Y(冯绍元). New ideas and development tendency of theory for water saving in modern agriculture and ecology. J Hydraulic Eng (水利学报), 2004, (12): 1-7 (in Chinese with English abstract)

[2] Liu D-Y(刘殿英), Shi L-Y(石立岩), Dong Q-Y(董庆裕). The effect of top-dressing and irrigation time on the root system, root activities and plant characters in winter wheat. Acta Agron Sin (作物学报), 1993, 19(2): 149-155 (in Chinese with English abstract)

[3] Cai H-J(蔡焕杰), Kang S-Z(康绍忠), Zhang Z-H(张振华), Chai H-M(柴红敏), Hu X-T(胡笑涛), Wang J(王键). Proper growth stages and deficit degree of crop regulated deficit irrigation. Trans CSAE (农业工程学报), 2000，16(3)：24-27 (in Chinese with English abstract)

[4] Meng Z-J(孟兆江), Jia D-L(贾大林), Liu A-N(刘安能), Pang $\mathrm{H}-\mathrm{B}$ (庞鸿宾), Wang H-Z(王和洲), Chen J-P(陈金平). Effect of regulated deficit irrigation on physiological mechanism and water 
use efficiency of winter wheat. Trans CSAE (农业工程学报), 2003, 19(4): 66-69 (in Chinese with English abstract)

[5] Li B-F(李百凤), Feng H(冯浩), Wu P-T(吴普特). Studies on optimum low limits of soil moisture index for deficit irrigation of crops. Agric Res Arid Areas (干旱地区农业研究), 2007, 25(3): 227-231 (in Chinese with English abstract)

[6] JieY-L(接玉玲), Yang H-Q(杨洪强), Cui M-G(崔明刚), Luo X-S(罗新书). Re1ationship between soil water content and water use efficiency of apple leaves. Chin J Appl Ecol (应用生态学报), 2001, 12(3): 387-390 (in Chinese with English abstract)

[7] Shan L(山仑), Kang S-Z(康绍忠), Wu P-T(吴普特). Water Saving Agriculture in China (中国节水农业). Beijing: China Agriculture Press, 2004. pp 229-230 (in Chinese)

[8] Liu Z-J(刘增进), Li B-P(李宝萍), Li Y-H(李远华), Cui Y-L(崔 远来). Research on the water use efficiency and optimal irrigation schedule of the winter wheat. Trans CSAE (农业工程学报), 2004, 20(4): 58-63 (in Chinese with English abstract)

[9] Hou L-T(侯连涛), Jiang X-D(江晓东), Han B(韩宾), Jiao $\mathrm{N}-\mathrm{Y}$ (焦念元), Zhao C(赵春), Li Z-J(李增嘉). Effects of different mulching treatments on the gas exchange parameters and water use efficiency of winter wheat. Trans CSAE (农业工程学报), 2006, 22(9): 58-63 (in Chinese with English abstract)

[10] Wang J-S(王建生), Xu Z-K(徐子恺), Yao J-W(姚建文). Analysis of food throughput per unit water use. Adv Water Sci (水科学进 展), 1999, 10(4): 429-434 (in Chinese with English abstract)

[11] Sun H-Y(孙宏勇), Liu C-M(刘昌明), Zhang Y-Q(张永强), Zhang X-Y(张喜英). Study on soil evaporation by using microlysimeter. $J$ Hydraulic Eng (水利学报), 2004, (8): 114-118 (in Chinese with English abstract)

[12] Duan A-W(段爱旺). Measuring leaf area index of crop colony. Irrig \& Drainage (灌溉排水), 1996, 15(1): 50-53 (in Chinese with English abstract)

[13] Liu Y-J(刘彦军). The effectts of irrigation rate and time on war consumption and output of wheat. J Hebei Agric Sci (河北农业 科学), 2003, 7(2): 6-11 (in Chinese with English abstract)

[14] Zhang Z-X(张忠学), Wu W-L(吴文良). Optimal irrigation regime for yield improving and water saving in winter wheat. Irrig \& Drainage (灌溉排水), 2001, 20(3): 20-24 (in Chinese with English abstract)

[15] Liu G-S(刘庚山), Guo A-H(郭安红), Ren S-X(任三学), An S-Q(安顺清), Lin R-N(林日暖), Zhao H-R(赵花荣). The effect of limited water supply on root growth and soil water use of winter wheat. Acta Ecol Sin (生态学报), 2003, 23(11): 2343-2352 (in Chinese with English abstract)

[16] Zhang S-Q(张胜全), Fang B-T(方保停), Wang Z-M(王志敏), Zhou S-L(周顺利), Zhang Y-H(张英华). Influence of different spring irrigation treatments on water use and yieldformation of late-sowing winter wheat. Acta Ecol Sin (生态学报), 2009, 29(4): 2035-2044 (in Chinese with English abstract)

[17] Yang J C, Zhang J H, Huang Z L, Zhu Q S, Wang L. Remobilization of carbon reserves is improved by controlled soil-drying during grain filling of wheat. Crop Sci, 2000, 40: 1645-1655

[18] Panda R K, Behera S K, Kashyap P S. Effective management of irrigation water for wheat under stressed conditions. Agric Water Manag, 2003, 63: 37-56

[19] Li F M, Liu X L, Li S Q. Effects of early soil moisture distribu- tion on the dry matter partition between root and shoot of winter wheat. Agric Water Manag, 2001, 49: 163-171

[20] Xu Z Z, Yu Z W, Wang D, Zhang Y L. Nitrogen accumulation and translocation for winter wheat under different irrigation regimes. J Agron \& Crop Sci, 2005, 191: 439-449

[21] Hu M-Y(胡梦芸), Zhang Z-B(张正斌), Xu P(徐萍), Dong B-D(董宝娣), Li W-Q(李魏强), Li J-J(李景娟). Relationship of water use efficiency with photoassimilate accumulation and transport in wheat under deficit irrigation. Acta Agron Sin (作物 学报), 2007, 33(11): 1884-1891 (in Chinese with English abstract)

[22] Turner N C. Further progress in crop water relations. Adv Agron, 1996, 58: 293-338

[23] Turner N C. Plant water relations and irrigation management. Agric Water Manag, 1990, 17: 59-73

[24] Fan X-M(范雪梅), Jiang D(姜东), Dai T-B(戴廷波), Jing Q(荆 奇), Cao W-X(曹卫星). Effects of nitrogen supply on flag leaf photosynthesis and grain starch accumulation of wheat from its anthesis tomaturity under drought or water logging. Chin J Appl Ecol (应用生态学报), 2005, 16(10): 1883-1888 (in Chinese with English abstract)

[25] Zhou L-Y(周凌云). Water consumption and water use efficiency of wheat field in Fengqiu region. Chin J Appl Ecol (应用生态学 报), 1995, 6(suppl): 57-61 (in Chinese with English abstract)

[26] Fang Q-X(房全孝), Chen Y-H(陈雨海), Li Q-Q(李全起), Yu $\mathrm{S}-\mathrm{Z}$ (于舜章), Luo $\mathrm{Y}$ (罗毅), $\mathrm{Yu} \mathrm{Q}$ (于强), Ou-Yang Z(欧阳竹). Effects of soil moisture on radiation utilization during late growth stages and water use efficiency of winter wheat. Acta Agron Sin (作物学报), 2006, 32(6): 861-866 (in Chinese with English abstract)

[27] Musick J T, Jones O R, Stewart B A, Dusek D A. Water-yield relationship for irrigated and dryland wheat in the US Southern Plains. Agron J, 1994, 86: 980-986

[28] Oweis T, Zhang H, Pala M. Water use efficiency of rainfed and irrigation bread wheat in a Mediterranean environment. Agron J, 2000, 92: 231-238

[29] Sun H Y, Liu C M, Zhang X Y, Shen Y J, Zhang Y Q. Effects of irrigation on water balance, yield and WUE of winter wheat in the North China Plain. Agric Water Manag, 2006, 85: 211-218

[30] Han Z-J(韩占江)，Yu Z-W(于振文), Wang D(王东), Zhang Y-L(张永丽). Effects of soil moisture esting and supplemental irrigation on dry matter accumulation and distribution and water use efficiency in winter wheat. Chin J Appl Ecol (应用生态学报), 2009, 20(11): 2671-2677 (in Chinese with English abstract)

[31] Liu H(刘浩), Duan A-W(段爱旺), Gao Y(高阳). Soil evaporation variation and estimating model from winter wheat field in intercropping patterns. Trans CSAE (农业工程学报), 2006, 22(12): 34-38 (in Chinese with English abstract)

[32] Wan C-J(万长建), Zheng Y-F(郑有飞), Zhang J-J(张建军). Analysis and calculation on law of transpiration rate of wheat. Agric Meteorol (中国农业气象), 1998, 19(6): 10-13 (in Chinese with English abstract)

[33] Wang H-X(王会肖), Liu C-M(刘昌明). Experimental study on crop photosynthesis, transpiration and highefneient water use. Chin J Appl Ecol (应用生态学报), 2003, 14(10): 1632-1636 (in Chinese with English abstract) 